\title{
Bur open Premature retirement due to ill health and income poverty: a cross-sectional study of older workers
}

\author{
Deborah J Schofield, ${ }^{1}$ Emily J Callander, ${ }^{1}$ Rupendra N Shrestha, ${ }^{1}$ \\ Richard Percival, ${ }^{2}$ Simon J Kelly, ${ }^{2}$ Megan E Passey ${ }^{3}$
}

To cite: Schofield DJ, Callander EJ, Shrestha RN, et al. Premature retirement due to ill health and income poverty: a cross-sectional study of older workers. BMJ Open 2013;3:e002683. doi:10.1136/bmjopen-2013002683

- Prepublication history for this paper is available online To view these files please visit the journal online (http://dx.doi.org/10.1136/ bmjopen-2013-002683)

Received 4 February 2013 Revised 18 April 2013 Accepted 19 April 2013

This final article is available for use under the terms of the Creative Commons Attribution Non-Commercial 2.0 Licence; see

http://bmjopen.bmj.com

${ }^{1}$ NHMRC Clinical Trials Centre, University of Sydney, Camperdown, New South Wales, Australia

${ }^{2}$ National Centre for Social and Economic Modelling, University of Canberra, Australian Capital Territory, Australia

${ }^{3}$ University Centre for Rural Health (North Coast), University of Sydney, Lismore, New South Wales, Australia

Correspondence to Dr Emily Callander; emily.callander@ctc.usyd. edu.au

\section{ABSTRACT}

Objectives: To assess the income-poverty status of Australians who were aged between 45 and 64 years and were out of the labour force due to ill health.

Design: A cross-sectional study using a microsimulation model of the 2009 Australian population (Health\&WealthMOD).

Setting: 2009 Australian population.

Participants: 9198 people aged between 45 and 64 years surveyed for the 2003 Survey of Disability, Ageing and Carers.

Primary outcome measures: $50 \%$ of the median equivalised income-unit-income poverty line.

Results: It was found that individuals who had retired early due to other reasons were significantly less likely to be in income poverty than those retired due to ill health (OR $0.4395 \% \mathrm{Cl} 0.33$ to 0.51 ), and there was no significant difference in the likelihood of being in income poverty between these individuals and those unemployed. Being in the same family as someone who is retired due to illness also significantly increases an individual's chance of being in income poverty.

Conclusions: It can be seen that being retired due to illness impacts both the individual and their family.

\section{BACKGROUND}

The health, unemployment and poverty relationship is complex and multidimensional. Unemployment was found to lead to poor health in a longitudinal British study in the 1980s, ${ }^{12}$ with later Australian studies also demonstrating the adverse impacts of unemployment on mental health. ${ }^{3-7}$ There is additional evidence from the UK, Denmark, Germany and the USA of unemployment leading to depression, anxiety, cardiovascular disease, lung cancer, accidents and suicide. ${ }^{3} \quad 4 \quad 6-9$ Similarly, being in income poverty has also been identified as having a detrimental effect on overall health status. ${ }^{10-12}$

However, there is a small body of evidence of the inverse relationship, with ill health being identified as having a significant negative impact on people's labour force

\section{ARTICLE SUMMARY}

Article focus

- To assess the poverty status of those who have retired early due to ill health.

- To assess the influence of family type on the poverty status of those who have retired early due to ill health.

Key messages

- People who had retired due to reasons other than ill health, as well as those who were employed full-time and part-time, were all significantly less likely to be in income poverty than those retired due to ill health.

Key strengths and limitations of this study

- A key strength is the use of the microsimulation model, Health\&WealthMOD, which allowed the use of detailed health, economic and labourforce information at the micro (individual) level in the analysis.

- A key limitation is that the data were crosssectional, so causality could not be shown.

participation and income within Australia ${ }^{13-19}$ and internationally. ${ }^{20-22}$ However, it is not known how this impact on labour-force participation may follow through to affect income poverty status.

The potential for ill health to lead an individual into income poverty is important as chronic health conditions will affect the majority of individuals living in Western countries at some stage of their lives. For some of these individuals, the conditions may be severe enough to interrupt their normal working lifestyles, including forcing some individuals out of the labour force prematurely. Those aged 45-64 years who have a chronic-health condition are significantly more likely to be out of the labour force due to ill health than those without a chronic-health condition. ${ }^{23}$

It is well established that unemployment and low income can lead to ill health; 
however, there has been little research on exploring the potential of ill health to be a driver of income poverty through employment status. Exiting the labour force because of ill health is already known to be associated with poorer financial conditions both now and in the future, ${ }^{24}{ }^{25}$ so ill health has the potential to be a major driver of income poverty. Poverty is seen as a benchmark indicator of living standards within modern society. ${ }^{26}$ To be labelled as being in income poverty comes with an understanding by wider society that an individual is not coping financially and they have inadequate economic resources to support a decent standard of living. ${ }^{27}$ Leaving the workforce due to ill health may increase the chance of living in income poverty due to their poorer financial status. This paper will examine the relationship between being out of the labour force due to ill health and being in income poverty among members of the older working aged population, and assess the influence of family type on this relationship.

\section{METHODS}

This paper uses a microsimulation model-Health\& WealthMOD to assess the poverty status of those who were aged between 45 and 64 years and had retired due to ill health.

\section{Data source: Health\&WealthMOD}

Within Australia, there are no nationally representative data that contain detailed information on health status, income, poverty and not being in the labour force due to ill health. To fill this deficiency, Health\&WealthMOD was constructed based upon the 2003 Survey of Disability, Ageing and Carers (SDAC) - a nationally representative survey conducted by the Australian Bureau of Statistics $^{28}$ that contains detailed information on chronic-health condition, reasons for not being in the labour force and individual income range-and STINMOD—a nationally representative microsimulation model of continuous income, taxes, benefits and wealth. Health\&WealthMOD is a nationally representative microsimulation model of 45-64-year- old Australians in 2009 that captures their disability and illness status, as well as detailed income information, labour-force status, reasons for not being in the workforce and poverty status.

Information on 45-64-year-olds and their family members was taken from SDAC to form the base population of Health\&WealthMOD. The records were then uprated to represent the 2009 population, accounting for the changes in demographics that had taken place between 2003 and 2009. The uprating only accounted for the change in the number of people reporting health conditions that were due to the ageing of the population. Any change in the number of people reporting health conditions between 2003 and 2009 that was related to trend increases or a decline in illness was not captured by uprating. However, the proportion of the
Australian population reporting a long-term health condition has remained stable in more than 10 years between 1995 and 2007/2008, so the authors had no reason to believe that the portion of people reporting a long-term health condition would increase between 2003 and $2009^{29}$ beyond the impact of age.

This base population of Health\&WealthMOD was then combined with STINMOD, another microsimulation model that contains detailed economic information. STINMOD is Australia's leading static microsimulation model of nationally representative tax and cash transfer information, ${ }^{30}$ which is maintained and further developed for the Commonwealth by the National Centre for Social and Economic Modelling and is routinely used by Commonwealth departments for assessing the distributional and revenue implications of tax and cash transfer reforms. The model operates at the 'micro' level of families and individuals, and uses Australian Bureau of Statistics income survey unit record files as the base population. STINMOD contains a range of additional economic information such as continuous data on individual income, government support payments, income tax liability, values of individuals' financial assets such as cash, superannuation, shares, property investment and owner-occupied home.

The economic information from STINMOD was linked to the base population by a microsimulation method call synthetic matching. ${ }^{31}$ It is not possible to match individuals between STINMOD and SDAC for several reasons. Both are based on survey information, and so there would be few respondents in common on both data sources; also, the data were collected at different points in time, meaning that even for the few individuals in common, some variables (such as age and marital status) will no longer be the same between SDAC and the surveys underpinning STINMOD. Furthermore, for privacy reasons, exact matching between the Australian Bureau of Statistics surveys is prohibited and the Australian Bureau of Statistics removes all identifying information from individual-level data. ${ }^{32}$

Records from STINMOD were matched to records from Health\&WealthMOD by matching on a number of variables that were common to the two data sets. In this case, nine matching variables were chosen: labour-force status, income-unit type, type of government pension/ support, income quintile, age group, sex, hours worked per week, highest educational qualification and home ownership-based on their strong association with income. Once the records were matched, the economic information from STINMOD was transferred onto the base population of Health\&WealthMOD. For a more detailed account of the process by which Health\&WealthMOD was created, see Schofield $e t a l^{33}$

\section{Measuring poverty}

To identify the individuals in the 45-year-old to 64-year-old Australian population that were in income poverty in 2009, an income poverty line based on $50 \%$ 
of the median income unit income was used in conjunction with OECD-modified equivalence scales. ${ }^{16}{ }^{34}$ The income unit is defined by ABS as "a group of two or more related persons in the same household assumed to pool their income and savings and share the benefits deriving from them equitably; or one person assumed to have sole command over his or her income, consumption and savings." 28

This income poverty line was calculated by STINMOD, in order to ascertain the poverty line based upon the entire Australian population. The $50 \%$ of median-income poverty line expresses the economic situation of those in poverty relative to those in the middle of the income distribution. Those who were in income poverty had less than half the income of those in the middle of the income distribution of the population. Only $50 \%$ of the median income has been widely used as a poverty line both in Australia and internationally. ${ }^{35-37}$

While we assessed how many individuals were in income poverty, considering an individual's personal income is not seen as a true reflection of an individual's economic situation. Within a family, it can be assumed that members pool their economic resources for the benefit of all members-thus, looking at the wider income of the whole family will be more accurate. ${ }^{38}$ Owing to this assumption of the sharing of economic resources, the income unit's income will be used rather than the individual's income in this analysis (the terms 'income unit' and 'family' are interchangeable in the remainder of this paper as they both refer to an income unit as defined above). Members of the same income unit were identified within SDAC and the personal income of all adult members (aged 15 and over) of the family was tallied to obtain the 'income unit' or 'family' income.

Differences in the number and composition of families were accommodated for using equivalence scales. ${ }^{39}$ The OECD-modified equivalence scale ${ }^{40}$ was utilised in this study, whereby a value of 1.0 was given to the first adult member (person aged 15 years and over), a value of 0.5 to each subsequent adult family member and a value of 0.3 to each child (person aged under 15 years). The family's income was divided by their equivalence score, thereby equivalising the income and allowing comparisons between families of different sizes.

If a family is identified as being in income poverty, then all family members are considered to be income poverty. This has important implications for identifying the relationship between retiring early due to ill health and poverty status-if retiring early due to ill health reduces the family's income below the poverty line, then the entire family is considered to be in income poverty.

\section{Statistical analysis}

The 2003 SDAC recorded individual labour-force participation. For those who stated that they were 'not in the labour force', their main reason for not being in the labour force was recorded. Response options included: retired, study or returning to study, own ill health or disability, childcare availability or children too young or prefers to look after them, too old, does not need or want to work, some else's ill health or disability, other family considerations, pregnancy, lacks relevant schooling, training or experience, do not know and other. In this study, those who were out of the labour force and stated that their main reason for this was their own ill health or disability were considered to be 'out of the labour force due to ill health'; and those who selected all other options were considered to be 'out of the labour force due to other reasons'.

Members of the 45-year-old to 64-year-old Australian population were grouped into one of five groups based on their labour-force status: employed full-time, employed part-time, unemployed (not employed but looking for work), not in the labour force due to ill health and not in the labour force due to other reasons. The proportion of the 45-year-old to 64-year-old Australian population that was in poverty in each group was estimated.

Logistic regression models were used to compare the odds of being in poverty for those who were employed full-time, part-time, unemployed and not in the labour force for reasons other than ill health. Not in the labour force due to ill health was used as the reference group so that the difference in OR of being in poverty between these individuals and those in other labour force categories could be determined. The outcomes were adjusted for age group, sex and education (having at least a bachelor's degree, or not).

The analysis was then limited to those not in the labour force due to ill health. Logistic regression models were used to compare the odds of being in income poverty for those in different family types-married with dependants, married without dependants, single with dependants, single without dependants. Those who were married without dependants were used as the reference group. The outcomes were adjusted for age group, sex and education (having at least a bachelor's degree, or not).

ORs were presented with their $95 \%$ CIs and statistical tests were two-sided with the significance set at the 5\% level. Population estimates were expressed in the nearest hundred.

\section{RESULTS}

Within Health\&WealthMOD, there were 2242 individuals in income poverty; once weighted to represent the 45-year-old to 64-year-old Australian population in 2009, there were 1.313 million individuals in income povertyor $24 \%$ of this population.

In 2009, there were 431300 individuals aged 4564 years who were not in the labour force due to ill health. The majority, $73 \%$, of the individuals who were not in the labour force due to ill health were in income poverty. Only the unemployed had a greater proportion in income poverty-79\%. Those employed part-time 
Table 1 OR of being in poverty, adjusted for age, sex and education for the Australian population aged 45-64 years, 2003

\begin{tabular}{|c|c|c|c|c|c|}
\hline Employment status & $\begin{array}{l}\text { Weighted } \\
\text { population }\end{array}$ & $\begin{array}{l}\text { Percentage of } \\
\text { population in poverty }\end{array}$ & $\begin{array}{l}\text { OR of being in } \\
\text { poverty }\end{array}$ & $95 \% \mathrm{Cl}$ & p Value \\
\hline $\begin{array}{l}\text { Not in the labour force due to } \\
\text { ill health }\end{array}$ & 431300 & 73 & REFERENCE & & \\
\hline Employed full-time & 2657000 & 4 & 0.02 & 0.01 to 0.02 & $<0.0001$ \\
\hline Employed part-time & 961800 & 15 & 0.08 & 0.06 to 0.10 & $<0.0001$ \\
\hline Unemployed & 107300 & 79 & 1.26 & 0.73 to 2.16 & 0.4021 \\
\hline $\begin{array}{l}\text { Not in the labour force due to } \\
\text { other reasons }\end{array}$ & 1266600 & 51 & 0.43 & 0.33 to 0.56 & $<0.0001$ \\
\hline
\end{tabular}

and full-time had the lowest proportion in income poverty $-15 \%$ and $4 \%$, respectively. Around half of the individuals who were out of the labour force for reasons other than ill health were in income poverty, which is a lower proportion than the $73 \%$ of those who were in out of the labour force due to ill health who were in income poverty.

Once adjusted for age, sex and education (table 1), those who were employed full-time, part-time or were out of the labour force for reasons other than ill health were significantly less likely to be in income poverty than those who were out of the labour force due to their ill health. The OR of being in income poverty compared with those not in the labour force due to ill health was very small for those employed full-time and part-time. Those employed full time had 0.02 times the odds of being in income poverty compared with those not in the labour force due to ill health (95\% CI 0.01 to 0.02 ). However, those not in the labour force for reasons other than ill health had 0.43 times the odds of being in income poverty (or had a $57 \%$ chance of being in income poverty) compared with those in the labour force due to ill health (95\% CI 0.33 to 0.56). The unemployed were the only group to not have significantly different odds of being in income poverty compared with those not in the labour force due to ill health (OR 1.26, 95\% CI 0.73 to 2.16).

When limited to those not in the labour force due to ill health, a similar proportion of people who were married without dependants, married with dependants or single with dependants were in income poverty $(62 \%$,
$62 \%$ or $59 \%$, respectively). However, $90 \%$ of those who were single without dependants were in income poverty. This was also the second largest group in income poverty (by family type), behind those who were part of a married couple without dependants (table 2).

After controlling for age, sex and education, those who were single had six times the odds of being in income poverty than those who were married (OR 6.28, 95\% CI 3.47 to 11.36). There was no significant difference in the odds of being in income poverty between those who were married with dependants, single with dependants, and those who were married without dependants (table 2).

When taking family members into account, there were 387100 individuals who were in income poverty, throughout the Australian population who had a member of their income unit aged 45-64 years who was not in the labour force due to ill health $(316,300$ who themselves are out of the labour force due to ill health, and an additional 173300 family members).

\section{DISCUSSION}

Poverty is a phenomenon experienced by nearly three quarters of the Australians aged 46-64 years who are not in the labour force due to their ill health-316 300 people. The financial impact of illness-related early retirement is not only borne by the individual-it also affects their entire family with 173300 individuals in the same family as much as someone not in the labour force due to ill health also being in income poverty. Those

Table 2 OR of being in income poverty compared with those married with dependant children*, 45-year-old to 64-year-old population not in the labour force due to ill health

\begin{tabular}{|c|c|c|c|c|c|c|}
\hline Family type & $\begin{array}{l}\text { Weighted-population } \\
\text { OT in poverty }\end{array}$ & $\begin{array}{l}\text { Weighted } \\
\text { population in } \\
\text { poverty }\end{array}$ & $\begin{array}{l}\text { Pecentage of } \\
\text { population in } \\
\text { poverty }\end{array}$ & OR & $95 \% \mathrm{Cl}$ & p Value \\
\hline Married couple only & 75700 & 123500 & 62 & REFERENCE & & \\
\hline $\begin{array}{l}\text { Married with } \\
\text { dependants }\end{array}$ & 17600 & 28600 & 62 & 1.16 & 0.52 to 2.61 & 0.7151 \\
\hline One person & 17500 & 157200 & 90 & 6.28 & 3.47 to 11.36 & $<0.0001$ \\
\hline $\begin{array}{l}\text { One parent, } \\
\text { dependants }\end{array}$ & 4600 & 6600 & 59 & 1.80 & 0.63 to 5.17 & 0.2722 \\
\hline
\end{tabular}


not in the labour force due to ill health who were single with no children were those most likely to be in income poverty $(90 \%)$. This emphasises the importance of having a partner to share the financial burden of not being in the labour force due to ill health, ${ }^{41}{ }^{42}$ and also the potential financial reliance that people who are not in the labour force due to ill health have on their partners. Interestingly, those who were single with dependent children were not significantly more likely to be in income poverty than those who were married. This may be because single parents who have poor health and dependent children up to the age of 8 years have higher welfare payments (Parenting Payments) and may have income support from a non-custodian parent. Within Australia, those who are unable to work because of a physical, intellectual or psychiatric condition, or those who are blind, are able to assess a Disability Support Pension. The rates of welfare payments are stratified by marital status, with those who are single or a member of a couple getting different rates or payment. ${ }^{434}$

Other studies linking health and poverty have discussed how the poor generally have worse health, and thus improving the health of these populations should be a goal to create greater equity in health. ${ }^{45}$ What these studies do not take into consideration is the specific impact that health has on labour force participation, particularly among older workers, which can influence the poverty status of individuals. That is, the impact of ill health on labour-force participation (and the associated loss of income and financial resources) is strongly associated with a higher incidence of poverty. While this study was undertaken using cross-sectional data, it is known that people not in the labour force due to ill health presently have higher rates of income poverty. Before these people left the labour force, it is unlikely that they would have been in income poverty-this paper has shown that only $4 \%$ and $15 \%$ of people employed full-time and part-time, respectively, were in income poverty.

The difference in the likelihood of being in poverty between those who are not in the labour force due to ill health and those who are so for other reasons suggests that it is being out of the labour force due to illness and not just being out of the labour force in general that increases the individual's chances of being in poverty. Those who are not in the labour force for reasons other than ill health fare better in terms of their poverty status than those not in the labour force due to illness. This may be due to the potential for greater choice to be exercised in whether or not the individual leaves the labour force before the traditional retirement age (65 years in Australia), and when this transition occurs (ie, this individual may decide to leave the labour force early due to a desire to pursue other interests, rather than being forced to leave due to an inability to work any longer due to restrictions imposed by illness). Such a choice may allow individuals to obtain a level of financial security that keeps them above the poverty line, for example, creating an investment portfolio that provides an income stream during retirement. Many individuals who retire early due to ill health are not well prepared financially; ${ }^{46}$ indeed, this is true for many beset by illness ${ }^{48}$ and, as such, may not have financial arrangements in place to finance-retirement periods. The onset, or even long-term experience, of ill health may cause families to reduce the financial assets they have accumulated that may have provided an income stream ${ }^{49}$-for example, the sale of investment properties (and the associated loss of rental income) to finance medical expenses associated with chronic illness.

Further to this, the additional economic burden imposed by illness in terms of medical costs is not captured by income-poverty lines. ${ }^{50}$ Those who do not have chronic-health conditions will not have the additional medical expenses of those not in the labour force due to ill health. ${ }^{51} 52$ The actual disposable income available to those not in the labour force due to ill health, once essential medical costs are taken into account, may reduce these individual's income even further and place more families in poverty or push some families further below the poverty line.

Contributors DJS conceived the study. RNS led the construction of the microsimulation model. EJC carried out the data analysis and drafted the manuscript. All authors provided expert advice on the design of the study and the interpretation of the results, and contributed to the drafting of the manuscript. All authors read and approved the final version of the manuscript.

Funding Sponsored by Australian Research Council and Pfizer Australia.

Competing interests None.

Ethics approval The use of the data in this manuscript was approved by the Australian Bureau of Statistics, with data for public release approved by the Microdata Review Committee.

Provenance and peer review Not commissioned; externally peer reviewed.

Data sharing statement The data used in this study came from Health\&WealthMOD, a microsimulation model constructed by the authors from the 2003 Survey of Disability, Ageing and Carers, and STINMOD. The 2003 Survey of Disability, Ageing and Carers is publicly available through the Australian Bureau of Statistics. STINMOD is publicly available through the National Centre for Social and Economic Modelling, University of Canberra. Enquiries regarding access to Health\&WealthMOD should be directed to Professor Deborah Schofield, deborah.schofield@ctc.usyd.edu.au.

\section{REFERENCES}

1. Moser K, Goldblatt P, Fox A, et al. Unemployment and mortality. In: Goldblatt $\mathrm{P}$, ed. Longitudinal study: mortality and social organisation. London: OPCS, 1990:82-96.

2. Moser K, Goldblatt P, Fox A, et al. Unemployment and mortality: comparison of the 1971 and 1981 longitudinal census samples. BMJ 1987;1:86-90.

3. Greatz. Health consequences of employment and unemployment: longitudinal evidence for young men and women. Soc Sci Med 1993;36:715-24.

4. Morrell S, Taylor R, Quine S, et al. A cohort study of unemployment as a cause of psychological disturbance in Australian youth. Soc Sci Med 1994;38:1553-64.

5. Banks M. Unemployment and the risk of minor psychiatric disorder in young people: cross-sectional and longitudinal evidence. Psychol Med 1982;12:789-98.

6. Linn M, Sandifer R, Stein S. Effects of unemployment on mental and physical health. Am J Pub Hth 1985;75:502-6. 
7. Iverson L, Anderson $\mathrm{O}$, Andersen $\mathrm{P}$, et al. Unemployment and mortality in Denmark. BMJ 1987;295:878-84.

8. Frese M, Mohr G. Prolonged unemployment and depression in older workers: a longitudinal study of intervening variables. Soc Sci Med 1987;25:173-8.

9. Bartley M. Unemployment and ill health: understanding the relationship. J Epidemiol Community Health 1994;48:333-7.

10. Buddelmeyer H, Cai L. Interrelated dynamics of health and poverty in Australia. Bonn, Germany: Institute for the Study of Labour, 2009.

11. McCelland A, Scotton R. Poverty and health. In: Fincher R, Nieuwenhuysen J, eds. Australian poverty: then and now. CarltonSouth: Melbourne University Press, 1998:185-202.

12. Saunders P. Disability, poverty and living standards: reviewing the Australia evidence, SPRC Discussion Paper No. 145. Sydney: Social Policy Research Centre (SPRC), 2005.

13. Cai L, Cong C. Effects of health and chronic disease on labour force participation of older working Australias. Aust Econ Papers 2009;48:166-82.

14. Cai L, Kalb G. Health status and labour force participation: evidence from the HILDA data. Melbourne Institute of Applied Economic and Social Research, 2004.

15. Council of Australian Governments National Reform Initiative Working Group. Human capital reform. Canberra: Council of Australian Governments, 2006.

16. Saunders P. Poverty, income distribution and health: an Australian study. SPRC Reports and Proceedings; Sydney: Social Policy Research Centre, 1996.

17. Schofield D, Callander E, Shrestha R, et al. The association between co-morbidities and labour force participation amongst people with back problems. Pain 2012;153:2068-72.

18. Schofield D, Callander E, Shrestha R, et al. Labour force participation and the influence of having back problems on income poverty in Australia Spine 2011;37:1156-63.

19. Schofield D, Callander E, Shrestha R, et al. Labour force participation and the influence of having CVD on income poverty of older workers. Int J Cardiol 2012;156:80-3.

20. van den Berg T, Schuring M, Avendano M, et al. The impact of ill health on exit from paid employment in Europe among older workers. Occup Environ Med 2010;67:845-52.

21. Schuring M, Burdorf L, Kunst $A$, et al. The effects of ill health on entering and maintaining paid employment: evidence in European countries. J Epidemiol Community Health 2007;61:597-604.

22. Gannon B. A dynamic analysis of disability and labour force participation in Ireland 1995-2000. Health Econ 2005;14:925-38.

23. Schofield D, Shrestha R, Passey M, et al. Chronic disease and labour force participation among older Australians. Med J Aust 2008;189:447-50.

24. Schofield D, Passey M, Percival R, et al. Retiring early with cardiovascular disease: impact on the individual's financial assets. Int J Cardiol 2011;146:125-6.

25. Brazenor R. Disabilities and labour market earnings in Australia. Aust J Labour Econ 2002:5:319-34.

26. Hagenaars A, de Vos K. The definition and measurement of poverty. J Hum Resour 1988;23:211-21.

27. Harding A, Lloyd R, Greenwell H. Financial disadvantage in Australian 1990 to 2000: the persistence of poverty in a decade of growth. Camperdown: The Smith Family, 2001.

28. Australian Bureau of Statistics. Information paper-basic confidentialised unit record file: survey of disability, ageing and carers 2003 (reissue). Canberra: Australian Bureau of Statistics, 2005

29. Australian Institute of Health and Welfare. Australia's health, 2010 Canberra: AIHW, 2010.

30. Percival R, Abello A, Vu QN. STINMOD (Static Income Model) 2007 In: Gupta A, Harding A, eds. Modelling our future: population ageing, health and aged care. Amsterdam: Elsevier B.V., 2007:477-82.
31. Rässler S. Statistical matching: a frequentist theory, practical applications, and alternative Bayesian approaches. New York Springer-Verlag New York, Inc., 2002.

32. National Statistical Service. Confidentiality: what is it and why is it important? Canberra: Australian Government, 2012.

33. Schofield D, Shrestha R, Callander E, et al. Modelling the cost of ill health in Health\&WealthMOD (Version II): lost labour force participation, income and taxation, and the impact of disease prevention. Int J Microsimulation 2011;4:32-6.

34. De Vos K, Zaidi MA. Equivalence scale sensitivity of poverty statistics for the member states of the European community. Rev Income Wealth 1997;43:319-33.

35. Saunders $P$, Bradbury B. Monitoring trends in poverty and income distribution: data, methodology and measurement. Econ Rec 2006;82:341-64.

36. Saunders P, Hill T, Bradbury B. Poverty in Australia: sensitivity analysis and recent trends. Sydney: SPRC, University of New South Wales, 2007.

37. Mejer L, Siermann C. Income poverty in the European Union: Children, gender and poverty gaps. Statistics in focus: population and social conditions: Eurostat. 2000.

38. Greenwell H, Lloyd R, Harding A. An introduction to poverty measurement issues. Canberra: National Centre for Social and Economic Modelling, 2001.

39. Trigger D. Does the way we measure poverty matter? Discussion Paper no 59. Canberra: NATSEM, 2003.

40. Hagenaars A, de Vos K, Zaidi MA. Poverty statistics in the late 1980s: research based on micro-data. Luxembourg: Office for Official Publications of the European Communities, 1994.

41. Henkens K. Retirement intentions and spousal support: a multi-actor approach. J Gentrol 1999;54B:S63-73.

42. Australian Bureau of Statistics. Summary of Findings. Retirement and retirement intentions, Australia, July 2006 to June 2007 ABS Cat No 62380. Canberra: ABS, 2008.

43. Department of Human Services. Parenting Payment. Secondary Parenting Payment. 2013. http://www.humanservices.gov.au/ customer/services/centrelink/parenting-payment

44. Department of Human Services. Disability Support Pension. Secondary Disability Support Pension. 2013. http://www. humanservices.gov.au/customer/services/centrelink/ disability-support-pension

45. Organisation for Economic Co-operation and Development (OECD) and the World Health Organisation (WHO). Poverty and health DAC Guidelines and Reference Series. Paris: OECD, 2003.

46. Kelly S, Schofield D, Shrestha R, et al. The impact of illness on retirement living standards. Econ Rec 2012;88:576-84.

47. Schofield D, Percival R, Passey $M$, et al. The financial vulnerability of individuals with diabetes. Br J Diabetes Vasc Dis 2010;10: 300-4.

48. Swoboda SM, Lipsett PA. Impact of a prolonged surgical critical illness on patients' families. Am J Crit Care 2002;11:459-66.

49. Mills A, Shillcutt S. Communicable diseases. In: Lomborg B, ed Global crises, global solutions. Cambridge: Cambridge University Press, 2004

50. Saunders P. The costs of disability and the incidence of poverty, SPRC Discussion Paper No. 147. Sydney: Social Policy Research Centre (SPRC), 2006

51. Graham S, Stapleton C. The extra costs of disability. In: Saunders P ed. Social policy in Australia, what future for the welfare state? Sydney: Social Policy Research Centre, University of New South Wales, 1990:103-12.

52. Wightman P, Robertson F. Costs of disability. A survey of the costs of disability for people with disabilities in labour force related activity, Policy Research Paper No.59. Sydney: Social Policy Research Centre (SPRC), 1996 